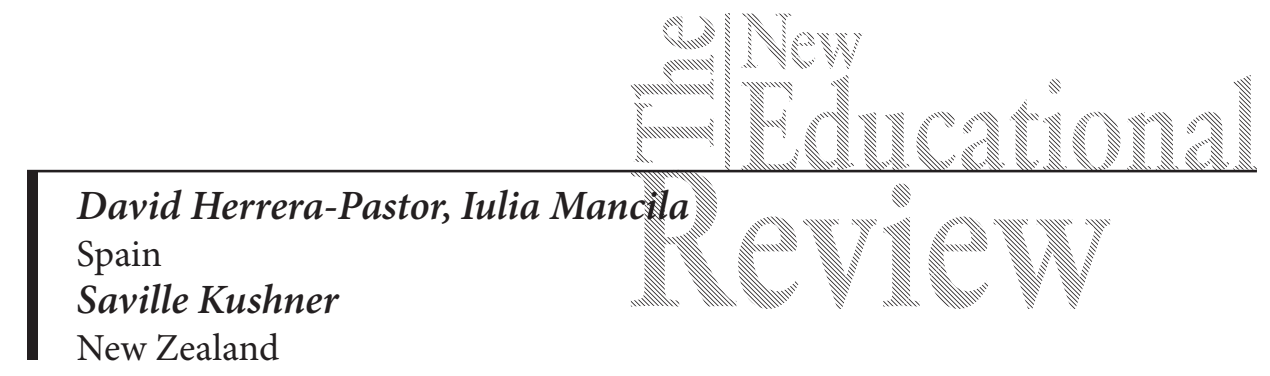

\title{
A Cross-Narrative Analysis in Biographical Inquiry - a Research Note
}

DOI: $10.15804 /$ tner.2017.48.2.23

\begin{abstract}
Many researchers argue that the analysis process of any narrative and biographical inquiry is a delicate, arduous and complex stage and requires creativity, advanced skills and the technique of the researcher. This research note, based on a research project carried out in Spain, makes a unique contribution to this debate by reflecting about the Cross-Narrative Model, whose father was Lewis (1973), introducing two concepts: Biographical Units and the Analysis Units. Furthermore, it describes the analysis process laying emphasis on the particular methodological challenges and possible benefits of using these units to build up a two-part biographical account. This research note concludes that the use of the Cross-Narrative Analysis model could be considered as a possible alternative to the on-going discussion on advancing the rigorous and resourcefulness narrative qualitative analysis endeavour.
\end{abstract}

Keywords: biographical research, inductive design, categorisation, cross-narrative model, research focus.

\section{Introduction}

The present paper is based on biographical research carried out in the south of Spain, on the rehabilitation experiences of Mohamed, a young man from Tunisia who, whilst still under-age, was arrested in Spain for drug trafficking. As a result, he was sentenced to a two-year rehabilitation process, divided into two separate 
orders: an initial stage at a detention centre, followed by a second stage of probation. Before completing the second stage, he began working in a care home for protected minors, initially as a monitor and then as an educator. Nowadays, he continues to work there (more than a decade after finishing the rehabilitation process).

One of the main reasons for carrying out this research was the evolution of the case: during the rehabilitation process the protagonist of the research went from being a "young offender" to being an "educator of minors". In this regard, we wanted to know just what had happened during the two rehabilitation stages in order for the story to unfold as it did. The study was not limited solely to experiences from this period. In order to truly understand the entire story and identify all key aspects, it was necessary to consider what had happened before and after his rehabilitation process to correctly interpret the overall effect of the protagonist experience in the youth justice system. There was a necessity to have the overview testimony of his whole life. That is why the biographical method was the most suited to this particular research. The challenge was to see the rehabilitation process in the context of his life, rather than define his life by the process (Kushner, 2000).

Apart from other information sources and data collection techniques, many interviews with key informants were carried out and numerous relevant documents gathered. Also, a significant number of photographs were used (mainly from Mohamed's experience in the detention centre).

This paper aims to share the following methodological particularities developed in the research. Most of them related to the way data were processed and organised:

- The research focus was not completely defined at the beginning. When the research started there was a field idea what to research, but early exchanges and emergent data shaped the precise research focus.

- A dual categorisation was carried out to organise the information: Biographical Units and Analytical Units were analytical tools created in this research to approach the huge amount of data.

- A variant of the Cross-Narrative model (the non-consecutive one) was set out to preserve the scientific character of the research

The synthesis process carried out to define the analysis categories will be shown. Also, a singular interpretation about their nature, aim and features will be stated. Finally, several interesting conclusions are developed with the aim of emphasizing the strengths and challenges of biographical research methodology. 


\section{Research Methodology}

\section{Research Design}

"If we understand design in its broadest sense of "planning of activities to be carried out in order to solve the problems or answer the questions raised» (Pérez Juste, 1985:71), then design becomes a bridge between the research question and the solution or answer given to it" (Rodríguez Gómez, Gil Flores y Garcia Jiménez, 1996: 61).

The design does not set out a predetermined process, which demands strict fulfilment of a pre-set trajectory, but rather aims to turn the development of the research into an emergent form (Stake, 2010).

Our research was carried out inductively, striving always for the data to guide the study. Since neither the key points which were to lead to this case evolving as it did nor the pedagogical elements involved were known beforehand, the aim was to locate and analyse those aspects which, in accordance with the biography, had been significant and had influenced Mohamed's evolution.

The biographical method is not characterised by having unique, rigid, inflexible procedures, but rather by using diverse data gathering instruments. Nor is it characterised by a relentless focus on the individuals whose life is being investigated rather, data sources included a large sample of the social structures through which he moved and was, himself, shaped. Interviews and documentary sources were the main sources of information, along with the photographs. It should also be stated that, apart from these sources, other materials and data collection instruments were used. In order to show all of them easily, the following summary table has been set:

Table 1. Summary of information sources and data gathering instruments

- 17 Interviews:

a) 5 biographical interviews with the protagonist

b) 12 semi-structured interviews with 17 key informants as follows:

- Mohamed's brother.

- The judge of the case.

- The deputy director of the Detention Centre (DC).

- A social worker at the DC, and later Mohamed's boss in the Association where he has worked since then.

- Mohamed's educator and tutor at the DC.

- An educator at the DC, and later a member of the Technical Team.

- Two monitors at the DC and now Mohamed's friends.

- A domestic service worker at the DC, and later Mohamed's foster mother.

- An educator who tutored Mohamed during his probation period. 
- An “Open Regime” technician.

- Mohamed's colleague, flatmate and friend.

- SWOT x 12

- Mohamed's iconographic records (over 200 photographs) + complementary interviews

- Unexpected information: a manuscript by Mohamed ("Meaning of work") + Interview.

- Official documents:

- Minors' Court file

- Youth Rehabilitation Board file

- Current legislation: Act 5/2000, of 12 January 2000, Regulating the Criminal Responsibility of Minors.

- Researcher's notebook

- DC Tutor Report (14 May 2001)

- Preliminary member check (twice with Mohamed and once with the other key informants).

- Biogram and Sociogram + Interview

Source: (Herrera-Pastor, 2016, pp. 147-148)

\section{Processing And Organising The Information}

Once most of the sources of information envisaged had been explored and an abundant amount of data had been obtained, a new phase began in the research. Specifically, it was necessary to draft the biography, which required starting to process and organise all the information collected up to this point at various stages as described below:

\section{Information Categorisation}

Once all the information had been transcribed, the categorisation process began. Pujadas (2002), following Lewis (1973), distinguishes between 'context units' and 'record units' within the categorisation process. Although he makes this distinction at a more advanced stage of the research and assigns to each of these units a different character to that envisaged below, it was nevertheless revealing given the fact that a dual categorisation of the different fragments of information could be a suitable way of starting that new research phase.

According to these authors, biographical research requires two tasks suitable to carry out a dual categorisation of the information: 1) Construct the biography and 2) Analyse data. The categorisation of each empirical document started by breaking down the information based on what has become known as 'Biographical Units' and 'Analytical Units'.

- Biographical Unit (BU) included each fragment of information of biographical interest. The biographical unit selected the part of the testimony, which 
could be used to draft a biography. The biography was drafted by combining the most appropriate biographical units of all the empirical papers.

- Analytical Unit $(A U)$ was considered to be the minimum expression of information, which could be scrutinised in line with the purposes of the research. Each AU included substantive content of interest related to Mohamed's life. It was the most elemental fragment of information established when drafting the list of 'analysis categories'.

Each analytical unit had its counterpart biographical unit, although not vice versa. Following this procedure, all the empirical documents were checked twice ${ }^{1}$, once for each type of 'unit' established. Once the scrutiny of each document was complete, a list of all the units extracted was drawn up, indicating the page where each one was located. This meant the units were easier to locate.

\section{Constructing the Biographical Account}

Constructing the core biography of a life history is a complex task. Every research has empirical particularities (Erben, 1998) and data does not speak by itself, it must be organised with sense (Bertaux, 1981; Roberts, 2002; Bolívar, Domingo and Fernández, 2001). It is important not to be swayed by the suggestive order of testimonies. A biography is a construction which has its own nature and requires logic, coherence and contextualisation, to make it intelligible and give meaning to the narration. As stated by Marinas and Santamarina (1993: 37-38), it is necessary to ensure that the account "gives the life history". Moreover, as Holt (2010) emphasises, the emplotment is a key element of the resulting narrative without losing what is real.

The construction of the biography would be developed following the biographical method of crossed-narrative. The aim was for the biography to develop within the account of the protagonist of the story, divided into different chapters (i.e. his voice would give shape to the structure of the narration). The expressions in the third person would be then inserted after Mohamed's testimony, making up the final part of each chapter. These testimonies would complement and/or contradict the expressions of the main actor in an interrelated manner. In short, initially, the intention was to configure the narrative based on the dialogue established between the different voices, which, interacting with fluidity would make the reading more vivid and dynamic.

${ }^{1}$ Reviewing all the empirical material twice meant it was possible, when deemed appropriate, to add, eliminate or modify a unit, and to question and/or corroborate the work completed. In short, it provided the categorisation process with further guarantees. 
As the biography would develop through the voice of the protagonist, the construction of the biographical account started by first drafting what became known as the 'Account in the First Person' (A1 $\left.{ }^{\text {st }}\right)$. This account was constructed using the information provided directly and solely by Mohamed. This account would be key to the crossing of other significant voices and information (a polyphonic system) in order to ensure a holistic life account (Herrera-Pastor, 2016).

The 'Account in the first person' was developed chronologically, differentiating three blocks identified in the 'biogram'2 as follows: Before the arrest, The youth rehabilitation process and After the orders.

\section{Methodological Dilemma}

Once the biographical and analytical units of each document were established, the challenge of crossing the accounts began, but the following methodological dilemma emerged in the development of this task:

At that moment of the research it was not known which information could be discarded. The analysis categories tree had not been defined, meaning we could not rule out any data and we were obliged to keep up with all the information.

Moreover, the third person data was overwhelming. Inserting such a massive amount of information after Mohamed's testimony in each chapter would have altered the essence of the model envisaged and it would have made it less interactive and dynamic.

Although drafting the biography in accordance with the biographical method of cross-narrative was considered as most suitable, it seemed that the particular circumstances of the case did not fit the selected model, at least in an orthodox manner. What could be done to overcome this situation? The solution was to revise, process and summarise the rest of the empirical material collected. This led us to drafting an 'Account in the Third Person' (A3rd), which included all the information which did not come directly from Mohamed, without having to discard any data at any time. The text would be presented after the Account in the $1^{\text {st }}$ Person', following a structure of chapters similar to that developed in the first part of the story, meaning it was possible to establish parallelisms and contrast the information from each source. ${ }^{3}$ The biography was therefore drafted based

2 "The biogram is a graphical, chronological structure of the events which have given structure to the life [of a person] (...). [This is a tool] with easy visual representational power which is objective, simplified and relevant" (Cortés and Medrano, 2007: 68).

3 However, the 'Account in the $3^{\text {rd }}$ Person' does not include 'Chapter X. Beyond friendship'. This chapter only appears in the 'Account in the $1^{\text {st }}$ Person'. Here Mohamed recounts his senti- 
on two accounts: the 'Account in the $1^{\text {st }}$ Person' and the 'Account in the $3^{\text {rd }}$ Person'. Although in the cross-narrative model the crossing of testimonies was carried out consecutively in each chapter, in this research the crossing of the information had to be done non-consecutively.

The drawback was that the narration would not be drafted as dynamically and interactively as was envisaged. The advantages were that it was possible to compare and establish inferences between data of counterpart chapters, and that it was not necessary to discard any type of information. This meant that a broader range of information could be crossed, allowing a holistic and exhaustive overview of the case. Moreover, this format clearly gave prominence to Mohamed's testimony, in keeping with his role as a "young offender" within the youth rehabilitation process. It should be remembered that one of the aims established in this work with a biographical method was to give voice to those who, due to different circumstances, often find themselves in a situation of invisibility. Furthermore, constructing the story in this way meant the protagonist of the research could be known in more detail since, as said above, the information used to construct the first account came solely from Mohamed. This meant the interpretation of the protagonist could be seen without any interference from testimonies of third parties This was an important aspect in the development of the research, since the personal characteristics of our protagonist were key to the analysis of the case.

\section{Analysing the Biographical Account}

Once the biography had been constructed, it was time to focus on analysing the information. The aim of this stage was to define a list of analytical categories in order to scrutinise all the substantive information included in the biographical account.

In this research the process was carried out in an inductive, emergent manner. The analytical categories were formed based on an information synthesis process (Goodson, 2004), grouping together all related data to a specific matter. The categories tree took shape taking into account content similarities and relations existing between the different items of information. At the same time, consideration was given to different nuances expressed at each moment. The framework of categories was to provide the opportunity to access any aspect, which may be analysed in its own complexity (Herrera-Pastor, 2016).

mental relationship with a girl he met at the time. That chapter was not included in the Account in the $3^{\text {rd }}$ Person', as it was not deemed relevant to the study. 
The analytical outline took shape in a progressive manner. The drafting of the category list comprised:
A. Analytical Units
B. Topics
C. Topic Blocks
D. Categories

\section{A. - Analytical Units}

Once the biography was complete, all the Analytical Units were duly put into place. This process of locating units of analysis resulted in two lists of AUs, one for each block of the biographical account: Account in the first person (A1 $\left.{ }^{\text {st }}\right)$ and Account in the third person (A3rd), which included a list of ideas which, in total, exceeded 50 pages: a total of 712 AUs and 64 photographs.

\section{B.- Topics}

The second step in the information reduction process was to establish the topics. All the Analytical units were carefully reviewed in order to produce a list of the different subjects they contained. These subjects were ordered by the main theme. Each topic could contain as many AUs as were related to the subject represented.

Given the overwhelming amount of information recorded, establishing the topics followed the same procedure as during the first stage of the categorisation process, i.e. independently in each account ( $\mathrm{A} 1^{\text {st }}$ and $\left.\mathrm{A} 3 \mathrm{rd}\right)$.

The 'Account in the $1^{\text {st }}$ person' resulted in 80 topics, each with their corresponding subtopics. This was reduced to 40 topics by improving synthesis capability for the 'Account in the 3rd Person', with each topic naturally having its corresponding subtopics, sub-subtopics, etc. This second round of establishing topics seemed to produce slightly better results in terms of relating the different subjects.

\section{C. - Topic Blocks}

The next stage in the synthesis process was to establish topic blocks. As can be imagined, this involved grouping together of topics with common characteristics.

A corpus of common analysis began to take shape once this step was complete (there were many similarities between the whittled-down topic blocks of the 'Account in the $1^{\text {st }}$ Person' and the 'Account in the 3rd Person'). Defining these topic blocks was a laborious task, which, apart from requiring an incalculable number of work hours, involved a lot of testing, checking, changing and amending. The definition of this structure was a fundamental achievement in terms of definitively establishing the analysis categories. 
D. - Analytical Categories

The fourth step of the categorisation process was to define the analytical categories list. The most significant aspects of this list are indicated below:

1. Firstly, five cross-sectional categories in the case, which had to be taken into account throughout the analysis process, were established.

2. Three different symbolic worlds were considered, corresponding to the three moments originally distinguished in the biogram. As the core of the research was the rehabilitation process experienced by Mohamed, it was necessary to pay attention not only to the framework in which this developed, but also to other aspects, which took place before and after this process. The aim was to understand why Mohamed's experience developed the way it did. There was, therefore, a set of three moments which needed to be understood both individually and jointly in order to suitably interpret and analyse the biography.

3. The social and pedagogical experiences which were brought into focus as a result of the orders imposed could be seen. The rehabilitation process experienced by Mohamed was divided into two stages: the first stage was 'Detention', and the second 'Probation'. These stages had a series of common experiences, each of a different kind, which were important in the development of the story. Each of these can be seen more graphically below (Figure 1).

The 'Analytical categories' were considered "initial" since they needed to be interpreted as starting points rather than final destinations. In no case were these categories fixed, immovable or rigid; on the contrary, they were considered a platform of key aspects in order to start the process. These categories helped to start the analysis, and were defined and specified during this process in line with the idiosyncrasy of the case.

\section{Focus Of Research (Turnaround)}

The focus of the research was changing during the categorisation process. The fundamental research question was: Which elements came together for this youngster to pass from being a "young offender" to becoming an "educator of minors"? Specifically, there was great interest in knowing what had happened from an educational and social perspective, during detention and probation, for the case to evolve in this manner.

Apart from scrutinising Mohamed's different experiences during that period, the aim was to show the relations existing between them and how they affected the development of each legal order and the rehabilitation process in general. In this 
Figure 1. Pedagogical and social experiences which were brought into focus during Mohamed's youth rehabilitation process

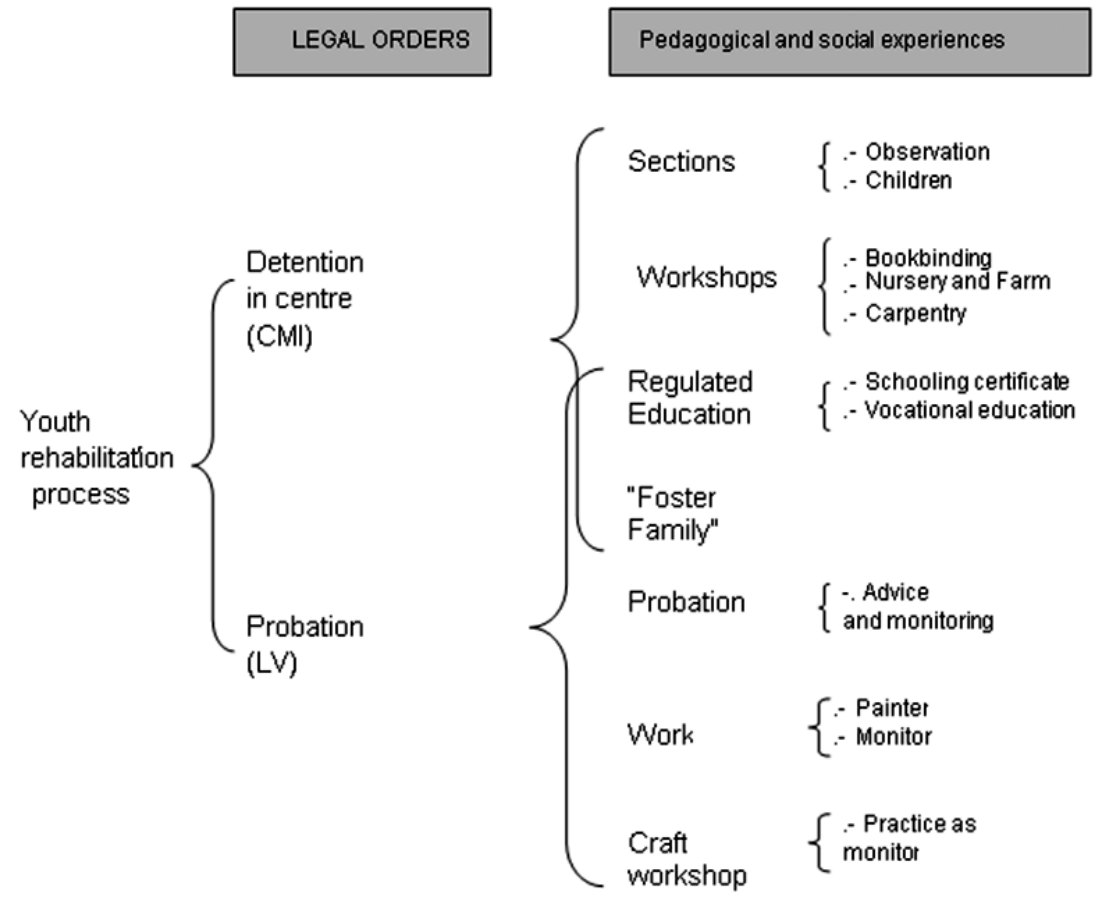

Source: (Herrera-Pastor, 2016, p. 156)

regard, it was believed that carrying out this analysis would provide access to the institutions in charge of implementing them, in order to see how they were carried out (in this case, a detention centre order and a probation order). There is a lack of understanding of work, which is carried out socially and pedagogically with "young offenders", and so this work should contribute to improving knowledge of this reality. Making this sort of practices known should shed light on experiences, which can be used as a reference by other professionals.

\section{Conclusions}

This paper seeks to share several methodological contributions to biographical research. They derive from a Life History project developed in Spain about the life of Mohamed, a young offender, who became "educator of minors" after undergoing 
a rehabilitation process. The research was set in an inductive manner; the different stages and procedures the data went through allowed us to define the research focus in an accurate way. In an inductive inquiry the research focus is determined progressively during the different research stages. The way the data was processed and organised in this research (all information had to go through different stages and was treated meticulously) allowed for the data to be analysed and re-analysed until a research focus emerged as a sense-making explanation. A synthesis process followed to set a list of shared analytical categories, incorporating our personal interpretations about how we consider them. The categories must be understood in accordance with the moment of research they correspond to, and, in consequence, viewed openly and flexibly. The categories are mechanisms which allow the researcher to navigate his or her way around the entire ocean of data.

Two methodological strategies have been developed in this research, both of which have proven to be fundamental to categorizing the huge amount of data, to analyse it and build the biography. These strategies were denominated as Biographical Unit (BU) and Analytical Unit (AU).

The Biographical Unit (BU) included the information of narrative interest that may, a priori, help to construct the story. The account was drafted by conjugating the different established BUs. Indeed, their organisation and treatment ultimately produced the biography.

The Analytical Unit (AU identified substantive information, which was open to analysis in accordance with the proposed research). It included data of interest for the study. This was the prime element used when drawing up the 'analysis categories' list. In general, it gave shape to the evidence, which was used during the examination of the data.

Each analytical unit had its biographical unit, although not the other way round (not all biographical units necessarily translated into analytical units).

Moreover, while we were using the Cross-Narrative model, we could not implement it in the orthodox manner, thus we worked out a way to cross data, in order to safeguard the scientific character of the research. The 'Cross-Narrative' model is a much more agile and dynamic narrative type than the 'Cross-Narrative (non-consecutive)' model developed in this research. However, the latter, despite paying less attention to literary interest and development of the narrative, offered reassurance from a scientific perspective by safeguarding the data and ensuring the validity of the research.

Finally, this inductive model could be potentially valuable for research projects where the amount of information is vast and/or there is no certainty with regards to which empirical records can be discarded when drafting the biography. It also 
may help to safeguard the essence of the biographical analysis model selected: crossing stories, comparing them in order to have a more insightful and rich framework of interpretation.

\section{References}

Bertaux, D. (1981). From Life-History Approach to the Transformation of Sociological Practice, In: D. Bertaux (ed.) Biography and Society the Life History Approach in the Social Sciences (pp. 29-47). London: Sage.

Bolívar, A., Domingo, J. y Fernández, M. (2001). La investigación biográfico-narrativa en educación. Enfoque y metodología.[Biographical and narrative research in education. Approach and methodology]. Madrid: La Muralla.

Cortés, A. y Medrano, C. (2007). Las historias de vida: fundamentación y metodología. En C. Medrano (coord.). Las historias de vida. Implicaciones educativas. [Life histories: foundations and methodology. In C. Medrano (coord.). Life histories. Educational implications]. (47-80). Buenos Aires (Argentina): Alfagrama edicions.

Erben, M. (1998). Biography and Education. A reader. London: Falmer Press.

Goodson, I. (2004). Historias de vida del profesorado. Problemas y posibilidades. [Studying Teachers' lives. Problems and possibilities]. Barcelona: Octaedro.

Herrera-Pastor, D. (2016). Aportaciones metodológicas a la investigación biográfica relacionados con el procesamiento y la organización de los datos.[ Methodological contributions to biographical research, related to the processing and organising of data]. Cuestiones pedagógicas, 25, 145-160

Holt, A. (2010). Using the telephone for narrative interviewing: a research note, Qualitative Research 10 (1): 113-121.

Kushner, S. (2000). Personalizing Evaluation. London: Sage.

Lewis, O. (1973). The children of Sanchez. México: Joaquín Mortiz.

Marinas, J.M. y Santamarina, C. (eds.) (1993). La historia oral: Métodos y experiencias.[Oral history. Methods and experiences]. Madrid: Editorial Debate.

Pujadas Muñoz, J.J. (2002). El método biográfico: El uso de las historias de vida en ciencias sociales.[Biographical method. The use of life histories in Social Science]. Madrid: Centro de Investigaciones sociológicas.

Rodríguez Gómez, G., Gil Flores, J. y García Jiménez, E. (1996). Metodología de la investigación cualitativa. [Qualitative research methodology].Málaga: Aljibe.

Roberts, B. (2002). Biographical Research. Buckingham / Philadelphia: Open University Press.

Stake, R. (2010). Qualitative Research. Studying how things work. New York/London: The Guilford Press. 